\title{
PENGARUH ALAT PERMAINAN EDUKATIF DAN MOTIVASI BELAJAR TERHADAP KREATIVITAS ANAK 5-6 TAHUN RA I'ANATUSH SHIBYAN AL-IRSYAD 2013
}

\author{
Sopiah $^{1}$ \\ ${ }^{1}$ Program studi PG- PAUD, Fakultas Ilmu Pendidikan Universitas MH. Thamrin
}

\begin{abstract}
ABSTRAK
Tujuan penelitian ini adalah untuk mencari bukti empiris tentang pengaruh alat permainan edukatif dan motivasi belajar terhadap kreativitas anak usia 5-6 tahun.Pada penelitian ini metode penelitian yang digunakan adalah metode eksperimen. Responden penelitian adalah anak usia 5-6 tahun di I'anatush Shibyan Al-Irsyad sebanyak 40 anak yang dipilih secara acak sederhana dari jumlah siswa keseluruhan 80 anak. Teknik pengumpulan data menggunakan untuk instrumen kreativitas adalah tes berupa soal dalam bentuk uraian dan instrumen motivasi belajar adalah angket dengan skala likert. Instrumen dikalibrasi dengan memakai uji validitas butir dan koefisien reliabilitas. Validitas butir dihitung dengan memakai koefisien korelasi product moment, sedangkan koefisien reliabilitas instrument dihitung dengan rumus Alpha Cronbach. Persyaratan analisis data diuji dengan normalitas populasi (uji Liliefors) dan dengan homogenitas varians populasi (uji Barlett). Analisis data menggunakan annava dua jalur.Hasil penelitian ini adalah sebagai berikut: (1) kreativitas anak yang diberi alat permainan edukatif buatan lebih tinggi daripada anak yang diberi alat permainan edukatif pabrik. Dari gambaran ini dapat dikatakan bahwa untuk meningkatkan kreativitas anak usia dini dapat digunakan alat permainan edukatif buatan; (2) Terdapat interaksi antara alat permainan edukatif dan motivasi belajar terhadap kreativitas anak usia dini, (3) Kreativitas anak yang diberi alat permainan edukatif buatan pada kelompok siswa yang memiliki motivasi belajar tinggi lebih tinggi daripada kelompok siswa yang diberi alat permainan edukatif pabrik. Dengan demikian untuk meningkatkan kreativitas anak usia dini yang memiliki motivasi belajar tinggi dapat menggunakan alat permainan edukatif buatan; (4) Kreativitas anak yang diberi alat permainan edukatif pabrik pada kelompok siswa motivasi belajar rendah lebih tinggi daripada kelompok siswa yang diberi alat permainan edukatif buatan. Dengan demikian untuk meningkatkan kreativitas anak usia dini yang memiliki motivasi belajar rendah dapat digunakan alat permainan edukatif pabrik.
\end{abstract}

Kata Kunci:Alat Permainan Edukatif, motivasi belajar dan kreatifitas

\section{Pendahuluan}

Penelitian ini bertujuan untuk mendapatkan gambaran tentang kemampuan kreatif anak usia dini. Secara operasional penelitian ini bertujuan untuk mengetahui Perbedaan kreativitas anak yang diberi alat permainan edukatif dari bahari alami dan bahan buatan pabrik pada Raudhatul Athfal. Pengaruh interaksi antara perlakuan dengan alat permainan edukatif dan tingkat motivasi belajar terhadap kemampuan kreativitas. Perbedaan kreativitas antara anak yang memiliki motivasi tinggi yang diberi APE alami dan APE buatan pabrik. Perbedaan kreativitas antara anak yang memiliki motivasi rendah yang diberi APE buatan pabrik dan APE alami.

\section{Kajian Literatur \\ Kreatifitas}

Tjandrasa mendefeniskan bahwa kreativitas adalah proses yang digunakan seseorang untuk mengekspresikan sifat dasarnya melalui suatu bentuk atau medium sedemikian rupa sehingga menghasilkan rasa puas bagi dirinya dan menghasilkan suatu produk yang mengkomunikasikan sesuatu tentang diri orang tersebut kepada orang lain. Jelaslah, hal ini bertaku bagi orang dewasa dan anak-anak.

Menurul Guilfbed, kreativitas sebagai kemampuan produksi divergen, yailu sensitivitas terhadap problem, kefasihan, kebaruan, fleksibilitas, organisasi dan elaborasi, redefinisi dan evaluasi. Skema ini bermanfaat kerena walaupun cenderung menekankan proses terhadap artefak biasanya terdapat produk disamping ada sebuah proses. Sejalan oengan Bruner dalam Rhodes.M juga menyebutkan harus efektif dengan kata lain harus diakui dalam hasil produktif dan beberapa proses.

Dengan demikian, kreativitas harus dianggap sebagai suatu proses adanya sesuatu yang baru, apakah itu gagasan atau benda dalam bentuk atau rangkaian yang harus dihasilkan.

\section{Motivasi}


Louther menyatakan bahwa strategi dalam membimbing siswa agar temotivasi secara ekstrinsik adalah sebagai berikut:1) mulai mengajar memperkenalkan TIK, 2) memonitor kemajuan dan memberi penguat, 3) menilai setiap tugas siswa dan memberikan komentar secara tertulis. Kegiatan-kegiatan tersebut diharapkan akan membangkitkan motivasi belajar siswa lebih meningkat lagi.

Menurut Uno motivasi belajar merupakan upaya langsung untuk membantu guru dan orang tua menentukan cara efektif membantu anak termotivasi untuk belajar. Hal ini dibutuhkan hubungan yang selaras antara orang tua dan sekolah, keduanya perlu dan saling melengkapi. Semakin orang tua memahami dengan baik dan mempelajari yang guru lakukan maka makin membantu anak-anak mereka termotivasi serta mempunyai motivasi yang tinggi dalam belajar.

Dari beberapa teori-teori motivasi belajar didapat kesimpulan bahwa yang dimaksud dengan motivasi belajar adalah dorongan yang timbul pada diri seseorang baik dari dalam diri sendiri maupun dari luar untuk mencapai hasil belajar yang optimal. Adapun ciri-ciri motivasi belajar pada penelitian ini yaitu : 1) adanya hasrat dan keinginan berhasil, 2) adanya dorongan dan kebutuhan dalam belajar, 3) adanya harapan dan cita-cita masa depan, 4) penghargaan dalam belajar, 5) adanya kegiatan yang menarik dalam belajar, 6) adanya lingkungan belajar yang kondusif sehingga memungkinkan siswa dapat belajar dengan baik.

\section{Anak Usia DIni}

anak usia 5-6 tahun termasuk anak usia dini yaitu anak yang dalam tugas perkembangannya telah mampu menunjukkan kreativitas, mampu membedakan mana yang benar dan mana yang salah serta mampu berinteraksi dengan lingkungannya

\section{Metode Penelitian}

Metode penelitian yang digunakan adalah metode eksperimen. Penelitian ini berupaya menjelaskan perbedaari kemampuan kreatif yang dimiliki anak, dengan variabel terikat kreativitas, variabei bebas pembelajaran dengan alat permainan edukatif, dan variabel atribut motivasi belajar.

Penelitian ini menggunakan desain dengan variabel bebas dibentuk menjadi dua faktor, sebagai faktor penyebab terkendali adalah alat permainan yang terdiri dari dua tingkat faktor yaitu alat permainan bahan alami dan alat permainan bahan buatan pabrik (A), sedang faktor yang lain variabel atribut diklasifikasi dengan faktor yang lain variabel atribut diklasifikasi menjadi dua faktor yaitu motivasi belajar tinggi dan motivasi belajar rendah (B).

Desain penelitian eksperimen ini menggunakan desain faktorial $2 \times 2$ dengen matrik rancangan eksperimen yang diadaptasi dari Ary $\mathrm{dkk}^{1}$ dan Suryabrata ${ }^{2}$ adalah sebagai berikut ini:

Tabel 3. Desain Penelitian dengan desain faktorial 2X2

\begin{tabular}{|c|c|c|}
\hline $\begin{array}{l}\text { Motivasi } \\
\text { Belajar }\end{array}$ & $\begin{array}{c}\text { Bahan } \\
\text { Alami } \\
\left(\mathbf{A}_{1}\right)\end{array}$ & $\begin{array}{c}\text { Bahan } \\
\text { Pabrik } \\
\left(\mathbf{A}_{2}\right)\end{array}$ \\
\hline Tinggi $\left(\mathrm{B}_{1}\right)$ & $\mathrm{A}_{1} \mathrm{~B}_{1}$ & $\mathrm{~A}_{2} \mathrm{~B}_{1}$ \\
\hline Rendah $\left(\mathrm{B}_{2}\right)$ & $\mathrm{A}_{1} \mathrm{~B}_{2}$ & $\mathrm{~A}_{2} \mathrm{~B}_{2}$ \\
\hline Rata-rata & $\mathrm{A}_{1}$ & $\mathrm{~A}_{2}$ \\
\hline
\end{tabular}

\section{Keterangan:}

$\mathrm{A}_{1} \quad=$ Perlakuan dengan alat Permainan alami

$\mathrm{A}_{2} \quad=$ Perlakuan pembelajaran dengan alat Permainan pabrik

$\mathrm{B}_{1} \quad=$ Motivasi belajar anak Tinggi

$\mathrm{B}_{2} \quad=$ Motivasi belajar anak rendah

$\mathrm{A}_{1} \mathrm{~B}_{1}=$ Kelompok anak yang diberi alat permainan edukatif alami yang memiliki motivasi belajar tinggi

$\mathrm{A}_{1} \mathrm{~B}_{2}=$ Kelompok anak yang memiliki yang diberi alat permainan edukatif buatan yang memiliki motivasi belajar rendah

$\mathrm{A}_{2} \mathrm{~B}_{1}=$ Kelompok anak yang diberi alat permainan edukatif pabrik yang memiliki motivasi belajar tinggi

$\mathrm{A}_{2} \mathrm{~B}_{2}=$ Kelompok anak yang diberi alat permainan edukatif pabrik yang memiliki motivasi belajar rendah ${ }^{3}$

\footnotetext{
1 Donald Ary,L,C. Jacobs, dan A. Razavish, Introduction to Research in Education (New york: CBS College Publishing, 1985), p.279,

2 Sumadi Suryabrata Metodologi Penelitian (Jakarta ; Raja Grafindo Persada, 1997), pp.50-52

${ }^{3}$ Sudjana, Disain dan Analisis Eksperimen (Bandung: Tarsito, 1985), p. 118
} 


\section{Hasil Penelitian Dan Pembahasan}

Pembahasan hasil penelitian dilakukan berdasarkan deskripsi data kreativitas anak dan hasil pengujian hipotesis seperti yang telah dipaparkan sebelumnya. Pembahasan hasil pengujian hipotesis penelitian lebih lanjut adalah sebagai berikut:

\section{Hipotesis Pertama}

Dalam penelitian ini ditemukan bahwa terdapat perbedaan Kreativitas anak antara kelompok yang diberi alat permainan edukatif buatan dengan kelompok anak yang diberi alat permainan edukatif pabrik. Hal ini dibuktikan dengan uji Anava dua jalur diproleh $F_{\text {hitung }}=8,54>F_{\text {tabel }}=7,27$ yang teruji secara signifikan pada $\alpha=0,01$.

Hal ini disebabkan karena alat permainan edukatif buatan anak dapat berkreasi sendiri permainan apa yang hendak dibuat dan dimainkannya dari bahan-bahan yang ada di sekitar mereka.Dengan anak membuat sendiri mainan yang akan dimainkannya maka timbul kreativitasnya. Sehingga jika dilakukan tes kreativitas, maka anak yang memiliki motivasi belajar yang tinggi diberi alat permainan edukatif buatan akan memiliki skor kreativitas yang tinggi.

Berbeda dengan alat permainan pabrik, anak hanya tinggal memainkan alat permainan yang sudah jadi. Tidak perlu lagi anak berkreasi permainan apa yang akan dibuat dan dimainkannya. Sehingga kreativitas anak kurang terasah.

\section{Hipotesis Kedua}

Hipotesis kedua yang menyatakan bahwa terdapat interaksi antara alat permainan edukatifdan motivasi belajardengan Kreativitas teruji, yakni dengan didapatkan nilaiF $F_{\text {hitung }}=63,88$ lebih besar dari $F_{\text {tabel }}=7,27$. Dengan demikian pemberian alat permainan edukatif harus memperhatikan motivasi belajar anak.

Anak yang memiliki motivasi belajartinggi yang diberikan alat permainan edukatifbuatan menujukan Kreativitas anak yang lebih besar daripada anak yang diberikan alat permainan edukatifpabrik. Sebaliknya, anak yang memiliki motivasi belajarrendah yang diberikan alat permainan edukatifbuatan menunjukkan kreativitas anak yang lebih kecil daripada anak yang diberikan alat permainan edukatifpabrik. Hal ini menunjukkan bahwa dalam memberikan alat permainan edukatif yang tepat harus memperhatikan motivasi belajar anak.

\section{Hipotesis Ketiga}

Hipotesis penelitian yang menyatakan bahwa kreativitas anak pada kelompok anak yang memiliki motivasi belajar tinggi yang diberikan alat permainan edukatif buatan lebih besar daripada kelompok anak yang diberikan alat permainan edukatif pabrik dapat diterima. Hal ini dapat dilihat pada besarnya rerata skor Kreativitas anak pada kelompok anak yang memiliki motivasi belajar tinggi yang diberikan alat permainan edukatif buatan lebih besar secara signifikan dibandingkan dengan kelompok anak yang memiliki motivasi belajar tinggi yang diberikan alat permainan edukatif pabrik.

Anak yang telah memiliki motivasi belajartinggi memiliki Kreativitas yang baik. Sehingga jika ditambah lagi dengan faktor eksternal yakni alat permainan edukatif buatan yang membuat anak berkreasi sendiri dengan bahanbahan yang disediakan. Sehingga daya imajinasi dan kreasinya muncul menambah kreativitas anak.

Sementara anak yang memiliki motivasi belajarrendah perlu dibantu oleh faktor eksternal yang lebih baik agar anak dapat muncul kreativitasnya. Karena anak memiliki motivasi belajar yang rendah maka anak sukar atau enggan untuk melakukan kreasi dari alat permainan buatan yang disediakan oleh guru, sehingga skor kreativitasnya pun menjadi rendah.

\section{Hipotesis Keempat}

Hipotesis keempat yang menyatakan bahwa Kreativitas anak pada kelompok anak yang memiliki motivasi belajar rendah yang diberikan alat permainan edukatif pabrik lebih besar daripada kelompok anak yang diberikan alat permainan edukatif buatan dapat ditolak.

Anak yang memiliki motivasi belajarrendah akan lebih terbantu dengan alat permainan edukatif buatan. Alat permainan edukatif buatan dapat meningkatkan motivasi belajar anak sehingga walaupun anak tersebut memiliki tingkat motivasi belajar rendah akan terbantu untuk meningkatkan kreativitasnya dengan dibimbing oleh guru. Sementara alat permainan pabrik kurang dapat meningkatkan motivasi belajar anak karena anak kurang untuk melakukan kreasi dari alat permainan yang disediakan oleh guru.

\section{Pembahasan}

Berdasarkan temuan hasil penelitian dan pembahasan kesimpulan di atas ternyata alat permainan edukatif dan motivasi belajar memberikan pengaruh yang signifikan terhadap kreativitas anak usia dini. Dengan demikian 
penelitian ini memberikan implikasi terutama pada perencanaan dan pengembangan alat permainan edukatif yang akan digunakan dalam meningkatkan kreativitas anak usia dini.

Temuan bahwa kreativitas anak yang diberikan alat permainan edukatif buatan lebih tinggi daripada siswa yang diberikan alat permainan edukatif pabrik memberikan implikasi terutama berkenaan dengan pemberian alat permainan edukatif yang tepat. Dalam hal ini peran guru sangat penting bahwa dalam meningkatkan kreativitas anak diperlukan alat permainan edukatif yang tepat.

Dalam penelitian ini ditemukan terdapat interaksi antara alat permainan edukatif dan motivasi belajar pengaruhnya terhadap kreativitas anak usia dini. Interaksi ini memberikan beberapa implikasi. Pertama, pemberian alat permainan edukatif yang sama pada semua anak tanpa mempertimbangkan motivasi belajar merupakan hal yang kurang menguntungkan bagi anak. Hal ini disebabkan karena pada kelompok siswa motivasi belajar tinggi, pemberian alat permainan edukatif buatan memberikan hasil kreativitas anak yang lebih tinggi daripada kelompok siswa yang diberikan alat permainan edukatif pabrik. Demikian sebaliknya, Pemberian alat permainan edukatif tanpa mempertimbangkan motivasi belajar anak dapat menguntungkan anak pada kelompok tertentu dan dapat merugikan anak pada kelompok yang lain. Kedua, sekalipun motivasi belajar anak telah dipertimbangkan, namun penerapan alat permainan edukatif yang kurang tepat juga akan berdampak pada hasil kreativitas anak.

Dengan demikian alat permainan edukatif yang tepat dalam meningkatkan kreativitas anak adalah apabila dalam menerapkan alat permainan edukatif tetap memperhatikan motivasi belajar anak.

\section{Kesimpulan}

Penelitian ini mengkaji pengaruh alat permainan edukatif dan motivasi belajar terhadap kreativitas anak usia dini pada RA B I'anatush Shibyan Al-Irsyad, Alat permainan edukatif yang diberikan berupa alat permainan edukatif buatan dan alat permainan edukatif pabrik.

Berdasarkan hasil uji hipotesis yang telah diuraikan pada bab sebelumnya, dapat ditarik kesimpulan sebagai berikut: (1) kreativitas anak siswa yang diberi alat permainan edukatif buatan lebih tinggi daripada anak yang diberi alat permainan edukatif pabrik. Dari gambaran ini dapat dikatakan bahwa untuk meningkatkan kreativitas anak usia dini dapat digunakan alat permainan edukatif buatan; (2) Kreativitas anak siswa yang diberi alat permainan edukatif buatan pada kelompok siswa yang memiliki motivasi belajar tinggi lebih tinggi daripada kelompok siswa yang diberi alat permainan edukatif pabrik. Dengan demikian untuk meningkatkan kreativitas anak usia dini yang memiliki motivasi belajar tinggi dapat menggunakan alat permainan edukatif buatan; (3) Kreativitas anak siswa yang diberi alat permainan edukatif pabrik pada kelompok siswa motivasi belajar rendah lebih tinggi daripada kelompok siswa yang diberi alat permainan edukatif buatan. Dengan demikian untuk meningkatkan kreativitas anak usia dini yang memiliki motivasi belajar rendah dapat digunakan alat permainan edukatif pabrik; (4) Terdapat interaksi antara alat permainan edukatif dan motivasi belajar terhadap kreativitas anak usia dini. Dapat disimpulkan bahwa untuk meningkatkan kreativitas anak usia dini dapat menggunakan alat permainan edukatif berupa alat permainan edukatif buatan dan alat permainan edukatif pabrik.

\section{Saran}

Berdasarkan kesimpulan dan implikasi penelitian di atas, maka dapat dikemukakan beberapa saran atas temuan penelitian ini sebagai berikut:

1. Bagi pendidik taman kanak-kanak, dalam upaya meningkatkan kreativitas anak usia dini hendaknya dapat menggunakan alat permainan edukatif yang tepat. Guru hendaknya dapat mengembangkan alat permainan edukatif melalui inovasi dalam mengembangkan media pembelajaran terutama alat permainan edukatif. Dalam menentukan alat permainan edukatif yang akan digunakan hendaknya guru juga mengetahui dan memperhatikan motivasi belajar anak.

2. Bagi Kepala TK, hendaknya dapat memberikan kesempatan pada guru untuk mengembangkan alat permainan edukatif yang digunakan sehingga kegiatan-kegiatan yang dilakukan dapat bervariasi dan menarik bagi anak.

3. Bagi peneliti selanjutnya, hendaknya dapat mengembangkan penelitian ini dengan meneliti faktor-faktor lain yang belum diteliti pada penelitian ini. Dalam hal ini masih banyak faktor-faktor lain yang dapat mempengaruhi kreativitas anak usia dini, seperti inteligensi.

4. Bagi masyarakat hendaknya lebih memanfaatkan bahan-bahan tidak terpakai untuk bisa dijadikan sebagai alat pembelajaran edukatif buatan sehingga orang tua tidak perlu membeli alat permainan edukatif buatan pabrik yang harganya relative mahal.

\section{Daftar Pustaka}


Akbar, Feni dkk. Kreativitas, Panduan Penyelenggaraan Program Percepatan Belajar. Jakarta: Grasindo, 2001.

Amabile, T.M. The Social Psychology of Creativity. New York: Spingerverlag 1983

Amstrong, Thomas. Setiap Anak Cerdas Panduan Membantu Anak Belajar Dengan Memanfaatkan MultipleIntelegencenya Terjemahan. Jakarta: PT. Gramedia Pustaka Utama. 2002. Setup Anak Cerdas Penerjemah: Rina Bintaran, Jakarta Gramedia pustaka 2002.

Ananta, Aris. (ed). Ciri Demografis Kualitas Penduduk dan Pembangunan Ekonomi. Jakarta: Lembaga Demografi FE UI, 1992.

Anggani Sudono, "APE yang Membangun Kreatif Anak", Makalah Seminar PAUD, 27 Desember 2005. Jakarta: Diknas.

Ankunto, Suharsimi. Prosedur Penelitian Suatu Pendekatan Praktek. Jakarta: Rineka Cipta, 2003. Dasar-dasar Evaluasi Pendidikan. Jakarta Bina Aksara, 1998.

Arsyad. Media Pengajaran. Jakarta: PT Raja Garfindo Persada, 1997.

Ary, Donald L,C; Jacobs, dan A. Razavish, Introduction to Research in Education. New york: CBS College Publishing, 1985.

Ayan, Jordan E. Bengkel Kreativitas. Bandung: Kaifa. Mizan Pustaka.. 2005.

Bastaman HD. Meraih Hidup Bermakna. Jakarta. Paramadina. 1996.

Campbel, Donald T dan Sanley, Julian C. Experimental and Quasi-Experimental Desaign For Research. Chicago: Rand McNally College Publishing Company, 1996.

Carl, B. Growing Up Gifted (C.E. Menil Publishing Company, A Bell. 1983.

Catron, Carol E. dan Alien, Jan. Early Childhood Curriculum A Creative Play Model. New Jersey, Merrill, 1999.

De Bord, Karen. Family, School, and Community Insolvent in School Age: http:/www.JDe.orpyi996. june/a.html.2007

Depdiknas, Program National Bagi Anak Indonesia (PNBAI), Bidang Pendidikan. Depdiknas, Jakarta: 2003.

Dewi, Melyna Surya Peranan Gerak Tari kreatif dan Minat Tari Kreatif Siswa Terhadap Keberhasilan Belajar Menari Siswa SLTP St Theresia, Jakarta. Universitas Indonesia, 2003

Diknas, Acuan Menu Pembelajaran Pada Pendidikan Anak Dini Usia (Menu Pembelajaran Generik). Jakarta: Direktorat PADU, 2002.

Dockett, Sue dan Fleer, Marilyn. Play and Pedagogy in Early Childhood Bending the Rules. Sydney: Harcourt, 2000.

Dorothy. Things to do Played Learn, London: Hamlyn. 2004.

Erickson E. H. Identity and Life Cycle. Selected Papers. Psycology isues. Vol I. New York International Universites Press. 1978.

Erikson, Erik. Chilhood and Society, dikutip tak langsung oleh Robert F. Biehier dan Jack Snowman, Psychology Applied to Teaching $7^{\text {th }}$ Edition, Boston: Hougthon Mifflin company, 1993.

Erlauer, Laura. The Brain-Compatible Classroom (e books), Virginia: ASCD: 2005. 
Jurnal Inovasi Pendidikan MH. Thamrin , 1; Februari 2017

Evita Singgih, Salim. "Kreativitas dan Sikap Kreatif dari Siswa Berbakat”, Makalah yang disampaikan dalam Simposium Pengembangkan Siswa Anak Berbakat, Jakaria. 29-30 Maret 2000.

Fisher, Elaine Flory. Aesthetic Awareness And The Child. Peacock Publisher. Inc. Washington University. 1978.

Freeman \& Munandar U. Cerdas dan Cemerlang. Jakarta. PT. Gramedia Utama Pustaka. 2002.

Kecerdasan Cemerlang. Jakarta. PT. Gramedia Pustaka Utama. 2002.

FX Sudarsono, Pengukuran Status Ekonomi dan Permasalahannya, Populasi, Nomor 2 Volume Tahun 1990. Yogyakarta: PPK UGM.

Gallagher .J.J. Issues In Gifted Education. California USA : Ventura. 1979.

Guilfbro, J.P. Way Beyond the IQ. Buffalo : Creativity Learning Press. 1977.

Guilford Dalam Depdikbud. Petunjuk Mengguncikan Peraga di Taman Kanak-Kanak. Jakarta: Dikbud: 2000.

Guilford,J. P. Way Beyond the IQ (Buffalo: Creative Learning Press. 1997.

Hadis, Aswin. Psikologl Perkembangan Anak. Dirjen Dikti. Proyek Pendidikan Tenaga Guru. Jakarta. 1995.

Hadjam, Noor Rachman. 'Peningkatan Mutu Pendidik Anak Usia Dini”, Jurnal ilmiah Direktorat PAUD, 2005.

Harjanto. Perencanaan Pengajaran. Jakarta Rineka Cipta, 1997.

Hoover, Sandier dan Dempsey. "Understanding Parent Involment from Parents Perspective, Parents News Februari 2000. http:www.npin.org/pnews/2008

http://www.nncc.org/Curriculum/better.play.html

Jainy Wood. ed. Guide For Parent And Teachers. London: World Books International, 1992.

Jalal, Fasli. "Makalah Perluasan Layanan Pendidikan Anak Usia Dini”. http://www.dwp.or.id/article.2002.

Jamaris, Martini. Perkembangan dan Pengembangan Anak Usia Taman Kanak-kanak, Jakarta: PPS. UNJ, 2004.

Kamaril, Cut. Makalah Kreativitas dan Pembelajaran Pada Anak Usia Dini, Jakarta PPS UNJ. 2006

Keer, Adams. Bring Out the Genius in Your Child. Hainlyn. London. 2006.

Konblum, William. Sociology in A Changing World. New York Holt: Richard and Winston Inc. 1988.

Labinowicz, E. D The Piaget Primer Thinking, Learner, and Teaching. California: Wesley Publishing Company, 1980.

Laura, Diane; Heroman, Cale The Creative. Washington DC: Teaching Strategies Four Edison. 2002

Indiawati, Yeni. "Kadoku Toys", http//www.mediapendidikan.Com.Edisi Juni2007

M Stone, Sandra J. Haying, A Kid's Curriculum, 2001 Activities For Young Cliildren Age 2-6. East Lake Avenue Glenview: United Stated Of America, 1993.

Mary Mayesky, Creativity Activities for Young Children. New York: Denmark Publisher,1990.

McManus, Jasoi, Ed Play Time. Virginia: Time-Life Books Inc. 1987. 
Jurnal Inovasi Pendidikan MH. Thamrin , 1; Februari 2017

Mihaly Csikszentmihaly. Creativity. Flow and the Psychology of Discovery and Invention (New York: Harper Collins Publisher, 1996.

MNEYC. Teaching Young Children Through Work and Play. http//www- naeeyc. or/resources/ey Iy/2001 /O 2. httm,2001,

Moshman, David. Adolescent Psychological Development: Rationality, Morality, and Identity New Jersey: Lawrence Erbium Associated, Inc., 2005.

Movies, K Janet R. The Excelence of Play. Bristol : Open University Press, 1995.

Munadar. S C. Mengembangkan Bakat dan Kreativitas anak Sekolah. Petunjuk Bagi Guru dan Orangtua. Jakarta: PT Grasindo, I992.

Kreativitas Pada Masa Pra Sekolah. Jakarta: Rineka Cipta. 1982.

Munandar, Utami. Pengembangan Kreativitas Anak Berbakat. Jakarta: Rineka Cipta, 2004.

Murwani, Santosa. Statistik Terapan. Jakarta PPS UNJ, 1999.

Nordhaus, Steven. Economic Development. http://www.zebras.ron/cbt/chl6.html.

Ormrod,, E, Educatioal Psychology. USA:Developing Learners, 2002.

P, Rahmita. "Pendidikan Usia Dini Hak Semua Anak”. Jurnal Ilmiah PAUD. Diknas: 2006.

Padlius, Robert James dan Pakem, Ari. Sosiologi of Education. New Jersey: Prentice-Hall, 1992.

Patmonodewo, Soemiarti, Pendidikan Anak Prasekolah. Jakarta: Rineka Cipta .2000.

Piirto, J. Those Who Create. Dayton, Ohio: Ohio Psychlogi Press .1992.

Rhodes, M. An Analysis of Creativity. Phi, Delta Kappan. 1961.

Rieber, Llyod P. "Seriously Considering Play” http://it.coe.uga.ftdu/irjeber/play.html, 2002.

, Llyod P. "The Value of Serious Play”, http://lt.coe.uga.edu/Irleber/valuc ofplav.html

Roger, Cosby S. and Sawyers, Janet K. Play in The Lives of Children. Washinton DC: National Association For The Young Children 1995.

Rogers.CR. Town's. A. Theory of Creativity. Vernon. (Ed). Creativity Middle Sex: Pinguin Books. 1982.

Rohani. Media Instruksional Edukatif. Jakarta Rineka Cipta. 1997.

S.C. Utami. Kreativitas dan Keberbakatan. Jakarta: Gramedia Pustaka Utama. 2002.

Sadiman. S. Media Pendidikan. Jakarta: CV Rajawali. 1998.

Saleb Kos dalam tesis hubungan antara SEE dan pengetahuan kesehatan Rumahtangga dan pemeliharaan lingungan sehat, PPS, UNJ 2001.

Santrock, John W. Life-Spam Devlopment Perkembangan Masa Hidup, Terj. Achmad Chusair. Jakarta, Gelora Aksara Pratama, 2002.

Scannapieco, Maria dan Carrick, Kelli Connel Understanding Child Maltreatment: An Ecological and Developmental Perspective. New York, Oxford University, 2005. 
Jurnal Inovasi Pendidikan MH. Thamrin , 1; Februari 2017

Seefeldt, Carol dan Galfer, Alice. Continuing Issues in Early Childhood Education. New Jersey: Prentice Hall, 1990.

Semiawan, C. Perspektif Pendidikan Anak Berbakat. Jakarta: Grasinda 1997.

. Memupuk Bakat dan Kreativitas Siswa Sekolah Menengah. Gramedia Jakarta, 1984.

, Belajar dan Pembelajaran dalam Taraf Usia Dini (Pendidikan Prasekolah dan Sekolah Dasar). Jakarta: Prenhallindo, 2002.

Setyawati, Edi. Mainan Tradisional: Ke Arah Peluang Pengembangamya, Lokakarya. Produk Budaya Indonesia, Jakarta, 2007.

Smith et. al dalam Jhonson, J. E. et. al, Play and Early Childhood Development. New York, Adclison Wesley Longman, 1999.

Soekanto, Soerjono. Sosiologi Suatu Pengantar. Jakarta: Raja Grafindo Persada, 1990.

Sudjana, Desain dan Analisis Eksperimen. Bandung: Tarsito, 1985.

Metoda Statistika. Bandung : Tarsito, 1992.

Sudono, Anggani. Peranan alat Permainan Edukatif bagi Anak Usia Dini. Buletin PAUD 2004.

Suryabrata, Sumadi. Metodologi Penelitian. Jakarta: Raja Grafindo Persada, 1997.

Suyanto, Slamet. Pendidikan Anak Usia Dini, Jakarta. Depdiknas. 2003.

Tedjasaputra, Mayke S. Bermain, Mainan dan Pemainan untuk Pendidikan Usia Dini. Jakarta: Gramedia, 2005.

Tjandrasa, G.. Melibatkan Anak Menjadi Kreatif. Semarang: Media Publishing, 2001.

Treffinger.D.J., Research on Creativity: Gifted Child Quarterly, 1986.

Triantoro, Safaria. Creativity Quetient, Panduan Mencetakan Kreatif. Edisi 1 Yogyakarta: Platinum Dignosia Media Baru, 2005.

Tristed Diane. et al; Creative Curriculum for Preschool, Washington DC: Teaching Strategis, Fourth Edition, 2002.

Wijayanti, Nurti. "Pemanfaatan Kardus Bekas sebagai APE pada kelompok bermain”, Jurnal ilmiah PTKNF, Vol I ;2006. Jakarta.

Wolfgang, Charles H. dan Wolfgang, Mary E. School for Young Children. Boston: Allyn and Bacon.

Yetti Rahelly, Hasil Belajar Mata Pelajaran IPS di kelas III SD Jurnal Pendidikan Anak Usia Dini, PPs UNJ, Vol 2, No 2, Mei 2004, 